\title{
Keeping faith in gene manipulation
}

There are good reasons to revise the way that gene therapy experiments receive public scrutiny. But altering the role of a body with a reputation for effective oversight must be done sensitively if it is not to undermine efforts to maintain public acceptance of the field.

VIRTUALLY from the day it was created in the mid-1970s, the Recombinant DNA Advisory Committee (RAC) of the US National Institutes of Health (NIH) has remained highly controversial within the scientific community. Initially, it was those who claimed that the potential health and environmental dangers of gene-splicing had been vastly overestimated by an imaginative public that led to demands for its dismantling, on the grounds that its activities imposed an unacceptable bureaucratic burden on researchers. More recently, the committee has turned its attention to the ethical dimensions of gene therapy. As it has done so, others have championed its abolition by arguing that the research raises few issues that cannot be adequately dealt with by more conventional regulatory bodies - and indeed that singling out gene therapy for special attention itself raises an unwarranted danger signal in the eyes of the public.

In both cases, critics of the RAC have been answered at two levels. One is that the promises - and threats - of genetic engineering are, thanks to the ability of recombinant DNA techniques to alter the essence of living organisms, qualitatively different from previous laboratory practices and clinical procedures. The second is that the RAC, while acting as a focal point of public concerns, has also helped to contain these concerns by providing a structured forum in which they can be safely debated. Indeed, it could be argued that the RAC's high-profile existence has helped to stave off demands for restrictive legislation whose existence has, in countries such as Germany, helped to stifle the birth of a nascent biotechnology industry.

Many may be tempted to dismiss the efforts of Harold Varmus, the director of NIH, to eliminate the RAC as a capitulation to the demands of abolitionists. It would be wrong to do so. Varmus's arguments, set out in a formal proposal published last week in the Federal Register (see page 195), are based on a careful analysis of both the strengths and weaknesses of the committee's activities. In essence, his case is that the RAC spends too much time studying the details of relatively uncontroversial experiments, and could focus its efforts more effectively on the broader health and ethical issues raised by novel applications of gene therapy, such as its use on unborn children, which may amount to inadvertent germ-line therapy.

To achieve this, Varmus is proposing a clear separation between regulatory and 'monitoring' responsibilities. The first would be transferred entirely to the Food and Drug Administration (FDA) (where much of it already resides). The second would remain at NIH, but would be passed to a new, more streamlined body, with the ungainly title of the Office of Recombinant DNA Activities Advisory Committee (OAC). In addition to regular meetings of its own, the latter would be responsible for identifying topics and participants for regular public conferences, each dedicated to a single topic related to the science and ethics of novel techniques and their clinical applications.

The attractions of this restructuring are obvious. For genetherapy researchers, it will provide a less burdensome regulatory framework. For the NIH, it will permit public discussion of novel research without, in its own words, having to give "a stamp of approval on the basis of a limited threat to human health or safety". The difficulty arises over the question of public scrutiny. One of the merits of the RAC has in the past been the way in which open discussion of individual experiments has given them a particularly robust form of public legitimation. Conducting the same debates within the privacy of FDA committees will not be the same.

The key issue at stake with gene therapy, over and above the relative merits of individual experiments or techniques, is the maintenance of public trust. There was a time when this could be sustained simply by following the advice of panels of scientific and ethical experts. But the world has become more sophisticated. The certainties from which expert advice is offered are no longer taken for granted; regulatory justice must not only be done - it must be seen to be done.

Ways of achieving this in practice inevitably vary from one country to another, depending on indigenous political and cultural traditions. France, for example, has tended to take a legislative approach, enshrined in the decision to give cell and gene therapies the status of pharmaceutical drugs under the Agence de médicament - the French equivalent of the FDA while requiring their use to comply with laws on the release of genetically modified organisms; excessive rigidity is said to be avoided by the informal flexibility with which laws are traditional interpreted on the ground.

In Germany, the situation is similar, except that the regulations have in the past been more demanding - reflecting sensitivities heightened by the genetic excesses of the Nazi era while their flexible interpretation is less widely accepted. Japan, also carrying a historical legacy, has felt the need to make significant efforts to secure public acceptability, with academic researchers facing two parallel sets of regulatory hurdles, one on behalf of the Ministry of Health and Welfare, the other of the Ministry of Education, Science and Culture. Britain has taken a less burdensome approach. But again the expected level of vigilance has been high, first through the Genetic Manipulation Advisory Group, most recently with the government's agreement, under pressure from parliament, to set up a broadranging Human Genetics Advisory Commission.

In the United States, the concern that appears to unite the critics of moves to eliminate the RAC is that removing decisions for novel gene-therapy protocols from direct public scrutiny threatens to undermine the very process by which public legitimacy is traditionally created.

Varmus's proposals indicate that he is far from deaf to these concerns. But it remains important that they are respected in whatever machinery evolves after the present consultation period. One requirement is that links between the FDA and the NIH's remaining oversight machinery should remain strong and transparent, ensuring that all initiatives requiring public scrutiny continue to receive it. A related suggestion is that the new body, rather than being represented as a clear break with the past, should be re-cast as the product of an evolutionary process. Perhaps keeping the name of the RAC, and, more importantly, providing some guarantees that its opinions will continue to wield influence, would reassure a sceptical public that the changes are for the best. 